Central European Journal of Energetic Materials, 2016, 13(2), 273-288

ISSN 1733-7178

e-ISSN 2353-1843

\title{
Considerations on Energy Deposition with the BAM-Fallhammer
}

\author{
Alexander von OERTZEN*, Thomas LEHMANN \\ Bundesanstalt für Materialforschung und -prüfung (BAM), \\ 12200 Berlin, Germany \\ *E-mail: alexander.von_oertzen@bam.de
}

\begin{abstract}
The BAM-Fallhammer is a mechanical device to test the impact sensitivity of explosives and to determine a sensitiveness level. By its construction it transforms potential energy into kinetic energy of an impacting hammer, then hitting the sample. Ideally the entire potential energy is available at the moment of impact and the supporting base is infinitely rigid. By this study we want to quantify how much a real Fallhammer deviates from the ideal concept, and what the differences between different Fallhammers in different laboratories are. This information has never been collected in a consistent way. The aim of the authors is to develop guidance on the mechanical properties of the Fallhammer, which can be used for different purposes such as internal quality control, validation of the correct functioning of the Fallhammer, preparation of Round-Robin tests and similar. An established and verified mechanical status of a Fallhammer would greatly improve the quality and comparability of results and Round-Robin tests on the impact sensitivity of explosives.
\end{abstract}

Keywords: explosives, impact sensitivity, BAM-Fallhammer, quality control

\section{Introduction}

The BAM-Fallhammer [1] is used to test the impact sensitivity of explosives and to determine a threshold value for the minimum impact energy needed to ignite the sample. When the drop weight, accelerated by gravity, hits the sample in a special confined mount, it is essential to know how much energy is actually available to cause ignition of the sample. This amount of energy is commonly 
calculated via the potential energy before the drop weight is dropped. However, some unknown amount of energy may be lost through friction with the guides or in the foundation of the instrument, which could mean that the sample was not subjected to the full amount of energy as calculated.

In order to know the kinetic energy of the drop weight just before hitting the sample container and right after the impact, a light barrier sensor was used to determine the downward and upward speeds of the drop weight as close as possible to the collision point. Such speed measurements have been performed for different weights and for different drop heights. The sample container was left empty with the two cylindrical surfaces in direct contact. These were called dry runs.

It has to be understood, that not necessarily all the previously available potential energy, or later kinetic energy, is fully transferred to the sample upon hitting the sample container. The processes at the moment of the impact are probably very complex, including deformation of grains of the sample, heating of the material due to deformation, and perhaps also heating of the cylinder surfaces as they experience the collision. The amount of energy inelastically transformed into deformation and heat, with respect to the sample, could in principle be determined by repeating the speed measurements with a sample between the cylinder faces, instead of with an empty sample container as it was done here.

This paper deals only with the determination of the frictional losses and the inelastic properties originating from the foundation of the Fallhammer. The other question, obviously also a very crucial question for the usefulness of the test outcome, is when to consider a reaction to be positive or whether the sample remained unaffected from the impact, is not addressed here.

\section{Measurement set-up}

With the help of the electronics laboratory of the Federal Institute for Materials Research and Testing (BAM) a device was constructed to record the speed of the drop weight of the Fallhammer by means of a light sensor barrier. Figure 1 shows the counting device with two separate counters. Figure 2 shows the position of the reflecting strip needed to trigger the counting device.

By design four events occurring at the light sensor are used in the following manner:

$1^{\text {st }}$ event: start counter no. 1

$2^{\text {nd }}$ event: stop counter no. 1

$3^{\text {rd }}$ event: start counter no. 2

$4^{\text {th }}$ event: stop counter no. 2 


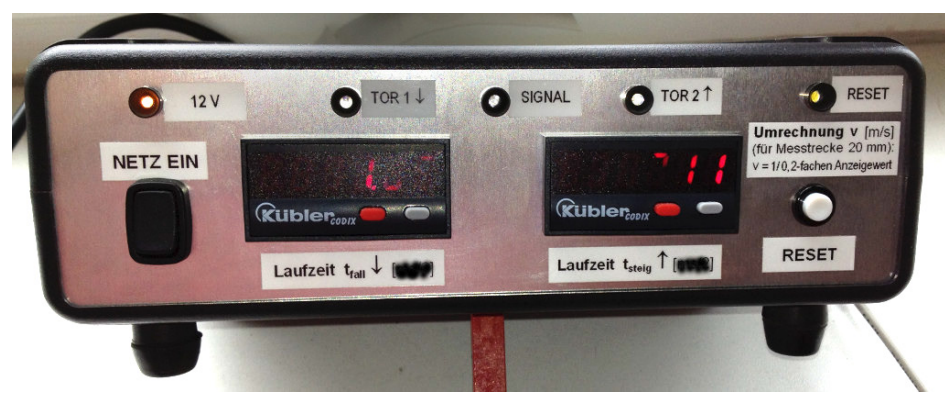

Figure 1. Counter device for the light sensor barrier.

The reflecting strip has two narrow reflecting areas with a given separation which will generate the above mentioned event sequence. As the drop weight moves downwards just before impact it passes the light sensor. The lower reflecting strip comes first in front of the light sensor and generates the $1^{\text {st }}$ event, while shortly after this the second reflecting strip passes and generates the $2^{\text {nd }}$ event. This records the time to pass the given separation distance and allows the downward speed to be calculated.

Then the impact occurs, the drop weight bounces back, and it swiftly moves in the upwards direction. The upper reflecting strip passes the sensor again and generates the $3^{\text {rd }}$ signal event, and as the drop weight and the strip travels further in the upwards direction, the lower reflecting strip will also pass the sensor generating the $4^{\text {th }}$ event. This time is stored in a separate counter (on the right) and allows the upward speed to be calculated. A reset button allows the counting device to be returned to the "ready" state.

The internal clock of the counter is $40 \mu$ s per counting impulse. The point separator of the display is set at two digits from the right, which means that a reading of 1.00 on the display corresponds to $4.00 \mathrm{~ms}$ between the respective start and stop events.

A strip with two reflecting lines exactly $20 \mathrm{~mm}$ apart has to be fixed by double-sided adhesive tape to the drop weight being dropped, while the light source and sensor need to be attached with a magnet to the frame of the Fallhammer. The reflecting material was taken from a printed circuit board (PCB). Figure 2 shows how this is attached to the drop weight. 


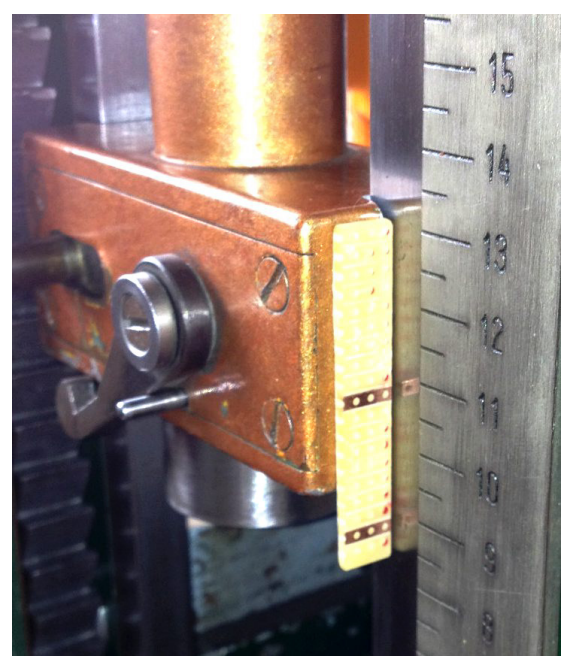

Figure 2. Reflector strip attached to the drop weight.

The placement of the sensor is shown in Figure 3, indicating the important dimensions which need to be taken into account. For the analysis the distance $h$ has to be known when the drop weight is at its lowest position, and should be close to $5 \mathrm{~mm}$. $h$ is the distance between the upper reflecting strip at its lowest point and the light sensor. The separation between the sensor and the reflective strip, denoted as $d$ in Figure 3, should be 5 to $8 \mathrm{~mm}$ for the sensor optics to operate reliably.

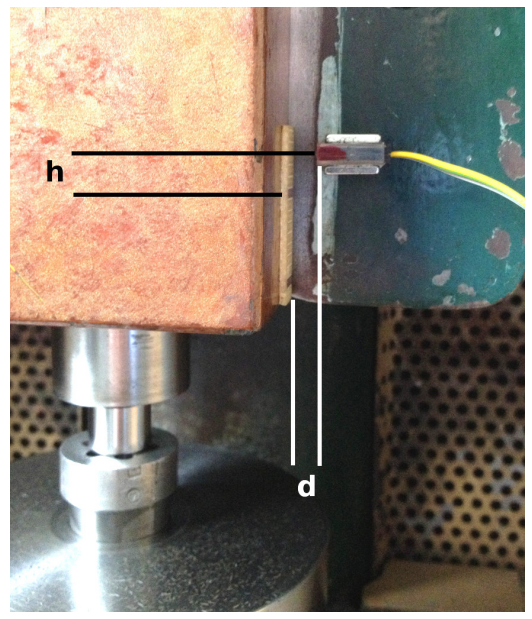

Figure 3. Placement of the light sensor and important dimensions. 


\section{Data analysis}

The analysis of the data was done by recording in a table the following data: the reading from the counter $\boldsymbol{c}$, the actual time $t$ in ms, and the calculated velocity $\boldsymbol{v}$ in $\mathrm{m} / \mathrm{s}$. This is done for both the down and up movements denoted by the index 1 and 2. Furthermore the theoretical speed $\boldsymbol{v}_{\boldsymbol{c}}$ calculated from the drop height $H$, taking into account the stand-off arising from the mounting of the strip, as an ideal acceleration without friction and air, and the $k$-value indicating the elastic efficiency of the foundation are displayed. An example for a drop height of $20 \mathrm{~cm}$ using the $5 \mathrm{~kg}$ drop weight is shown in Table 1.

Table 1. Example for data recording and analysis

\begin{tabular}{|c|c|c|c|c|c|c|c|}
\hline$c_{1}$ & $t_{1}[\mathrm{~ms}]$ & $v_{1}[\mathrm{~m} / \mathrm{s}]$ & $c_{2}$ & $t_{2}[\mathrm{~ms}]$ & $v_{2}[\mathrm{~m} / \mathrm{s}]$ & $v_{c}[\mathrm{~m} / \mathrm{s}]$ & $k$-value \\
\hline 2.66 & 10.64 & 1.880 & 2.99 & 11.96 & 1.672 & 1.956 & 0.7914 \\
\hline 2.64 & 10.56 & 1.894 & 3.01 & 12.04 & 1.661 & $\ldots$ & $\ldots$ \\
\hline 2.65 & $\ldots$ & $\ldots$ & & & & & \\
\hline
\end{tabular}

The calculated values are obtained by using the following formulas: with $g$ being the gravitational constant of $9.81 \mathrm{~m} / \mathrm{s}^{2}$.

$$
\begin{aligned}
& t_{i}=4 c_{i} \\
& v_{i}=20 \mathrm{~mm} / \mathrm{t}_{\mathrm{i}} \\
& v_{c}=\sqrt{(2 g(H-h))}
\end{aligned}
$$

The $k$-value is meant to indicate the energy return of the foundation where a value of 1 is full elastic return of the impacting energy, while a value of zero would mean full absorption of the impacting energy in the foundation. In order to have as much of the initial energy available this value should be as close as possible to 1 . The formula for $k$ is:

$$
k=\left(v_{2} / v_{1}\right)^{2}
$$

The value for $v_{1}$ should coincide with the calculated $v_{c}$. By forming a ratio between $v_{l}$ and $v_{c}$ an efficiency of the apparatus with regard to converting potential energy to kinetic energy can be calculated in addition to the above example of Table 1. In order to have an efficiency based on energy this value should be calculated as squared. In the following tables this value is labelled $q$.

Some remarks shall be made on measurement errors and uncertainties related to the measurement. The accuracy of the given length of $20 \mathrm{~mm}$ of the PCB 
reflector strip has been determined to be $\pm 0.1 \mathrm{~mm}$, or as a relative error $\pm 0.5 \%$. The accuracy of the time measurement is basically given by the resolution of the counting device, i.e. down to $\pm 40 \mu \mathrm{s}$, knowing that the time base of the counter is of a high accuracy. The relative error on time measurement, based on the shortest times measured, is then not more than $\pm 0.7 \%$.

The accuracy of the drop height $H$ is due to the nature of the ruler attached to the guides, estimated as $\pm 1 \mathrm{~mm}$. Together with the accuracy of the positioning of the light barrier sensor of $\pm 1 \mathrm{~mm}$ the total height measurement is assumed to have an error of not more than $\pm 2 \mathrm{~mm}$, or as a relative error based on the smallest drop height of $\pm 2 \%$. The overall relative uncertainty can be estimated slightly more precisely by taking into account, that for a low drop height the relative length error is higher, but the error in time measurement is lower, while for the higher drop heights the relative length error is less and the error in time is relatively larger. From this argument the total relative error would never exceed $\pm 2 \%$.

In this paper a comparison of different Fallhammers in different settings and foundations is presented. It is not known from first principle considerations, which values for the efficiencies should be expected and within which range values are acceptable. This study shall offer material for developing guidance.

\section{Results}

Firstly it should be stated that, even though a number of laboratories have been involved, this work is not meant as a Round-Robin test and has not been conducted under such prerequisites. The principal aim was to identify the value ranges for the assessment of the performance of a Fallhammer. Questions of repeatability in general, and of repeatability standard deviation, can only be addressed after further work has been done.

Another aspect to be mentioned is, that the measurements were all done in the presence of the authors and staff from each laboratory. The set-up of the timing device was done by the authors, the operation of the Fallhammer was done by the laboratory staff. Where an obviously loose part was identified, this was fixed before the data was recorded. Under the regime of a formal Round-Robin test following international standards such as ISO/IEC 17043 [2] or ISO 5725 [3] the test procedure should be different.

It was agreed among the participating laboratories, that their names may be mentioned, however, the resulting data would be anonymised. The participating laboratories were, in alphabetical order:

- Federal Criminal Police Office (BKA), in Germany 
- Federal Institute for Materials Research and Testing (BAM), in Germany

- Rheinmetall Waffe Munition GmbH, Branch Nico Trittau, in Germany

- Royal Military Academy (RMA), in Belgium

- Technical Center for Weapons and Ammunition (WTD 91), in Germany

The laboratories will be referenced by codes LAB-X, where $\mathrm{X}$ is one of the letters $\mathrm{B}, \mathrm{L}, \mathrm{M}, \mathrm{W}, \mathrm{T}$ and the coding is only known to the authors. The first set of results to be shown are from the LAB-L Fallhammer which has a concrete foundation reaching from the ground floor level, where the Fallhammer stands, down through the first basement level to the natural ground. Table 2 shows results for various drop heights and weights, which are averaged values from 10 drops each. The values in Table 2 have been rounded according to the relative measurement uncertainty (as detailed before of about 1-2\%), thus not showing any digits beyond the known accuracy.

Table 2. Results for the LAB-L Fallhammer

\begin{tabular}{|c|c|c|c|c|c|c|}
\hline $\begin{array}{c}\text { drop weight } \\
{[\mathrm{kg}]}\end{array}$ & $\begin{array}{c}\text { drop height } \\
{[\mathrm{cm}]}\end{array}$ & $v_{1}[\mathrm{~m} / \mathrm{s}]$ & $v_{2}[\mathrm{~m} / \mathrm{s}]$ & $v_{c}[\mathrm{~m} / \mathrm{s}]$ & $k$ & $q$ \\
\hline 1 & 10 & 1.24 & 0.96 & 1.37 & 0.60 & 0.83 \\
\hline 1 & 20 & 1.87 & 1.62 & 1.96 & 0.75 & 0.91 \\
\hline 1 & 30 & 2.34 & 2.03 & 2.41 & 0.75 & 0.94 \\
\hline 1 & 40 & 2.72 & 2.35 & 2.78 & 0.75 & 0.95 \\
\hline 1 & 50 & 3.10 & 2.59 & 3.12 & 0.70 & 0.99 \\
\hline 1 & 60 & 3.38 & 2.90 & 3.42 & 0.73 & 0.98 \\
\hline 1 & 70 & 3.70 & 3.08 & 3.69 & 0.69 & 1.00 \\
\hline 1 & 80 & 3.96 & 3.36 & 3.95 & 0.72 & 1.00 \\
\hline 5 & 10 & 1.23 & 1.08 & 1.37 & 0.78 & 0.81 \\
\hline 5 & 20 & 1.89 & 1.67 & 1.96 & 0.78 & 0.93 \\
\hline 5 & 30 & 2.37 & 2.07 & 2.41 & 0.76 & 0.97 \\
\hline 5 & 40 & 2.76 & 2.39 & 2.78 & 0.75 & 0.98 \\
\hline 5 & 50 & 3.10 & 2.68 & 3.12 & 0.75 & 0.99 \\
\hline 10 & 10 & 1.27 & 1.05 & 1.37 & 0.68 & 0.86 \\
\hline 10 & 20 & 1.88 & 1.54 & 1.96 & 0.67 & 0.92 \\
\hline 10 & 30 & 2.35 & 1.90 & 2.41 & 0.65 & 0.95 \\
\hline 10 & 40 & 2.73 & 2.18 & 2.78 & 0.64 & 0.96 \\
\hline 10 & 50 & 3.06 & 2.42 & 3.12 & 0.63 & 0.96 \\
\hline
\end{tabular}

Table 3 shows the results for the Fallhammer at LAB-B. 5 repetitions were done on each level and were averaged. A small difference of $v_{c}$ as compared with measurements at other laboratories originates from the slightly different 
height of the sensor (28 mm instead of $25 \mathrm{~mm}$ ). This Fallhammer is placed in an upper floor without a foundation reaching to natural ground. It was said that a strong construction beam is nearby, however, the building itself is a normal laboratory building.

Table 3. Results for the LAB-B Fallhammer

\begin{tabular}{|c|c|c|c|c|c|c|}
\hline drop weight $[\mathrm{kg}]$ & drop height $[\mathrm{cm}]$ & $v_{1}[\mathrm{~m} / \mathrm{s}]$ & $v_{2}[\mathrm{~m} / \mathrm{s}]$ & $v_{c}[\mathrm{~m} / \mathrm{s}]$ & $k$ & $q$ \\
\hline 1 & 20 & 1.76 & 0.87 & 1.94 & 0.25 & 0.82 \\
\hline 1 & 30 & 2.20 & 1.25 & 2.39 & 0.33 & 0.85 \\
\hline 1 & 40 & 2.60 & 1.71 & 2.77 & 0.44 & 0.88 \\
\hline 1 & 50 & 2.77 & 1.76 & 3.11 & 0.41 & 0.80 \\
\hline 1 & 60 & 2.90 & 2.07 & 3.41 & 0.50 & 0.73 \\
\hline 1 & 70 & 3.13 & 1.98 & 3.69 & 0.40 & 0.72 \\
\hline 1 & 80 & 3.04 & 1.78 & 3.94 & 0.34 & 0.61 \\
\hline 5 & 10 & 1.26 & 1.00 & 1.34 & 0.63 & 0.88 \\
\hline 5 & 20 & 1.87 & 1.55 & 1.94 & 0.67 & 0.93 \\
\hline 5 & 30 & 2.33 & 1.96 & 2.39 & 0.71 & 0.95 \\
\hline 5 & 40 & 2.70 & 2.28 & 2.77 & 0.71 & 0.95 \\
\hline 5 & 50 & 3.04 & 2.56 & 3.11 & 0.71 & 0.96 \\
\hline 5 & 60 & 3.36 & 2.81 & 3.41 & 0.70 & 0.97 \\
\hline 5 & 70 & 3.61 & 3.08 & 3.69 & 0.73 & 0.96 \\
\hline 5 & 80 & 3.88 & 3.21 & 3.94 & 0.69 & 0.97 \\
\hline 10 & 10 & 1.25 & 1.05 & 1.34 & 0.70 & 0.87 \\
\hline 10 & 20 & 1.88 & 1.59 & 1.94 & 0.72 & 0.94 \\
\hline 10 & 30 & 2.33 & 1.97 & 2.39 & 0.71 & 0.95 \\
\hline 10 & 40 & 2.71 & 2.29 & 2.77 & 0.71 & 0.96 \\
\hline 10 & 50 & 3.05 & 2.47 & 3.11 & 0.65 & 0.96 \\
\hline
\end{tabular}

Table 4 shows data recorded with the Fallhammer at $L A B-M$. This instrument has a solid concrete foundation sitting on natural ground. For each level 10 drops were performed and averaged. Only a $1 \mathrm{~kg}$ and $5 \mathrm{~kg}$ drop weight were used and only up to $50 \mathrm{~cm}$ drop height.

Another series of drop tests as dry runs was performed with the Fallhammer in the laboratories of LAB-T. Their Fallhammer is a custom made instrument which employs the same technical principle, but which is however less sophisticated and seems perhaps less massive. It is important to note, that for the lowest drop heights problems occurred in recording the upwards re-bound. In these cases the respective drop heights were skipped and the displayed data starts with the higher values. 
Table 4. Results for the LAB-M Fallhammer

\begin{tabular}{|c|c|c|c|c|c|c|}
\hline $\begin{array}{c}\text { drop weight } \\
{[\mathrm{kg}]}\end{array}$ & $\begin{array}{c}\text { drop height } \\
{[\mathrm{cm}]}\end{array}$ & $v_{1}[\mathrm{~m} / \mathrm{s}]$ & $v_{2}[\mathrm{~m} / \mathrm{s}]$ & $v_{c}[\mathrm{~m} / \mathrm{s}]$ & $k$ & $q$ \\
\hline 1 & 10 & 1.12 & 0.88 & 1.37 & 0.62 & 0.67 \\
\hline 1 & 20 & 1.64 & 1.37 & 1.96 & 0.70 & 0.70 \\
\hline 1 & 30 & 2.11 & 1.80 & 2.41 & 0.72 & 0.77 \\
\hline 1 & 40 & 2.52 & 2.14 & 2.78 & 0.72 & 0.82 \\
\hline 1 & 50 & 2.84 & 2.36 & 3.12 & 0.69 & 0.83 \\
\hline 5 & 10 & 1.29 & 1.09 & 1.37 & 0.71 & 0.89 \\
\hline 5 & 20 & 1.88 & 1.63 & 1.96 & 0.75 & 0.92 \\
\hline 5 & 30 & 2.33 & 2.03 & 2.41 & 0.76 & 0.94 \\
\hline 5 & 40 & 2.72 & 2.35 & 2.78 & 0.75 & 0.95 \\
\hline 5 & 50 & 3.03 & 2.62 & 3.12 & 0.75 & 0.94 \\
\hline
\end{tabular}

Table 5. Results for the LAB-T Fallhammer

\begin{tabular}{|c|c|c|c|c|c|c|}
\hline $\begin{array}{c}\text { drop weight } \\
{[\mathrm{kg}]}\end{array}$ & $\begin{array}{c}\text { drop height } \\
{[\mathrm{cm}]}\end{array}$ & $v_{1}[\mathrm{~m} / \mathrm{s}]$ & $v_{2}[\mathrm{~m} / \mathrm{s}]$ & $v_{c}[\mathrm{~m} / \mathrm{s}]$ & $k$ & $q$ \\
\hline 2 & 15 & 1.61 & 0.81 & 1.69 & 0.25 & 0.91 \\
\hline 2 & 20 & 1.89 & 1.01 & 1.96 & 0.29 & 0.93 \\
\hline 2 & 30 & 2.35 & 1.35 & 2.41 & 0.33 & 0.95 \\
\hline 2 & 40 & 2.73 & 1.62 & 2.78 & 0.35 & 0.96 \\
\hline 2 & 60 & 3.36 & 2.05 & 3.42 & 0.37 & 0.97 \\
\hline 2 & 80 & 3.88 & 2.39 & 3.95 & 0.38 & 0.96 \\
\hline 2 & 100 & 4.33 & 2.68 & 4.42 & 0.38 & 0.96 \\
\hline 2 & 120 & 4.75 & 3.00 & 4.84 & 0.40 & 0.96 \\
\hline
\end{tabular}

Figure 5 shows the data from the LAB-T Fallhammer as averages from 10 repetitions. The drop weights used did not follow the standard and the device is mainly used for verification tests. For very low impact energies a $0.25 \mathrm{~kg}$ drop weight was available, but was left outside the comparison. There is a temptation to use the calculated energies in Joules for a direct comparison between different drop weights. However, it is well known, that the impacting velocity also determines the reaction behaviour, and therefore multiplying the drop height with a factor, and dividing the weight by the same factor, is unlikely to yield comparable results.

The apparatus of LAB-W was located at ground level with a heavy basement and nothing below but natural ground. Table 6 shows the recorded data which are averages from 10 drops each. 
Table 6. Results for the LAB-W Fallhammer

\begin{tabular}{|c|c|c|c|c|c|c|}
\hline drop weight $[\mathrm{kg}]$ & drop height $[\mathrm{cm}]$ & $v_{1}[\mathrm{~m} / \mathrm{s}]$ & $v_{2}[\mathrm{~m} / \mathrm{s}]$ & $v_{c}[\mathrm{~m} / \mathrm{s}]$ & $k$ & $q$ \\
\hline 1 & 20 & 1.87 & 1.49 & 1.95 & 0.63 & 0.91 \\
\hline 1 & 30 & 2.27 & 1.83 & 2.40 & 0.65 & 0.89 \\
\hline 1 & 40 & 2.58 & 2.15 & 2.78 & 0.69 & 0.86 \\
\hline 1 & 50 & 2.85 & 2.35 & 3.11 & 0.68 & 0.84 \\
\hline 1 & 60 & 3.21 & 2.62 & 3.41 & 0.67 & 0.88 \\
\hline 1 & 70 & 3.51 & 2.92 & 3.69 & 0.69 & 0.91 \\
\hline 1 & 80 & 3.77 & 3.01 & 3.95 & 0.64 & 0.92 \\
\hline 5 & 10 & 1.26 & 1.10 & 1.36 & 0.76 & 0.86 \\
\hline 5 & 20 & 1.88 & 1.65 & 1.95 & 0.77 & 0.93 \\
\hline 5 & 30 & 2.34 & 2.06 & 2.40 & 0.78 & 0.95 \\
\hline 5 & 40 & 2.72 & 2.39 & 2.78 & 0.78 & 0.96 \\
\hline 5 & 50 & 3.05 & 2.67 & 3.11 & 0.77 & 0.96 \\
\hline 10 & 10 & 1.27 & 1.03 & 1.36 & 0.66 & 0.87 \\
\hline 10 & 20 & 1.88 & 1.56 & 1.95 & 0.69 & 0.93 \\
\hline 10 & 30 & 2.35 & 1.97 & 2.40 & 0.70 & 0.96 \\
\hline 10 & 40 & 2.74 & 2.32 & 2.78 & 0.72 & 0.97 \\
\hline
\end{tabular}

One observation from these tests, to be reported separately from the above, was that thorough maintenance of the Fallhammer plays an important role for the performance in terms of energy return. The highest possible degree of alignment of the guides, vertical alignment, regular lubrication with very thin silicon oil (rather than anything that could cause friction), and tightening of all screws and moveable parts seems to be indispensable. During some tests surprisingly strong deviations from the normal were observed. These could be almost completely eliminated by doing maintenance work on the spot, which had been forgotten for quite a while in that particular case.

\section{Data Analysis}

In order to facilitate a comparison of the results, the data from Tables 2-4 and 6 were converted to a graphical form, where for the same drop weight the energetic efficiency $(q)$ is shown for Fallhammers from different laboratories as the drop height is increased. Figure 4 shows data for the $1 \mathrm{~kg}$, Figure 5 for the $5 \mathrm{~kg}$, and Figure 6 for the $10 \mathrm{~kg}$ drop weight. The error bars show the standard deviation calculated from the 10 drops recorded (with the exception of LAB-B, where only 5 repetitions were done). 


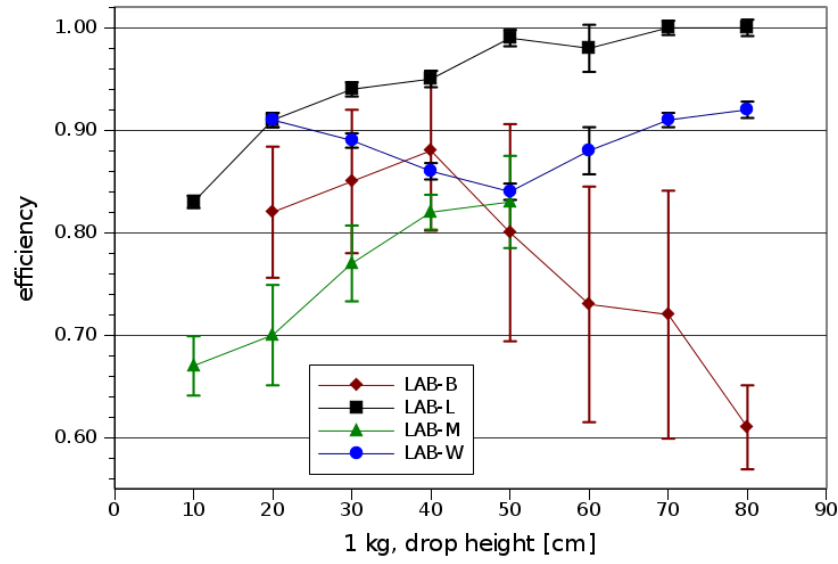

Figure 4. Efficiency (q) of conversion of potential energy to kinetic energy, $1 \mathrm{~kg}$.

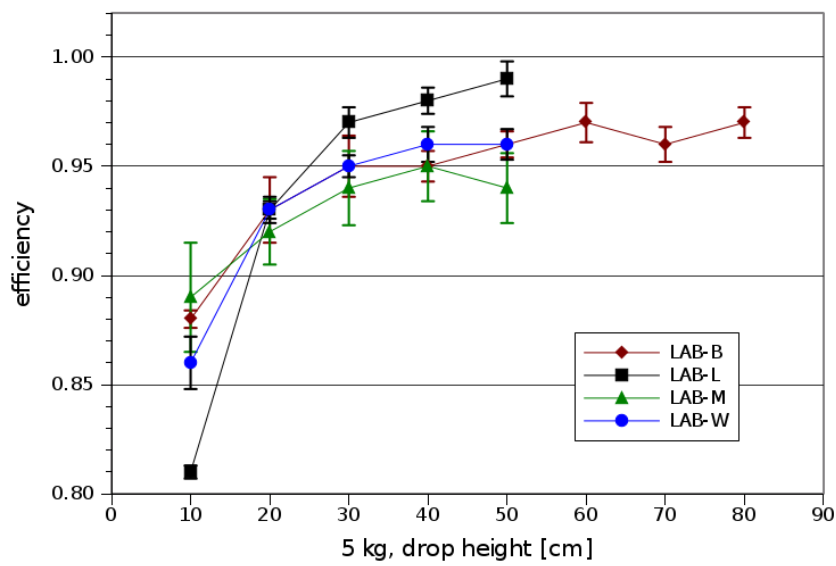

Figure 5. Efficiency (q) of conversion of potential energy to kinetic energy, $5 \mathrm{~kg}$.

The results show that, especially for the drop height of $10 \mathrm{~cm}$ and the $1 \mathrm{~kg}$ weight, only $80 \%$ or less of the nominal energy (calculated from the potential energy) is available for the impact. From $20 \mathrm{~cm}$ and above the efficiency lies around $90 \%$ and above. Figure 4 also shows, that the $1 \mathrm{~kg}$ drop weight requires a good state of maintenance of the Fallhammer, especially the guides, in order not to lose energy by friction.

Another technical aspect not looked at in this study, is at which point the actual release of the drop weight from the release mechanism takes place. Depending on the design of the release mechanism the drop weight could possibly be lowered by a few millimetre as the trigger is pulled and before it enters free 
fall. In such a case the $10 \mathrm{~cm}$ nominal height should be corrected to a smaller value, e.g. $9.5 \mathrm{~cm}$, changing the analysis in Figures 4-6 notably.

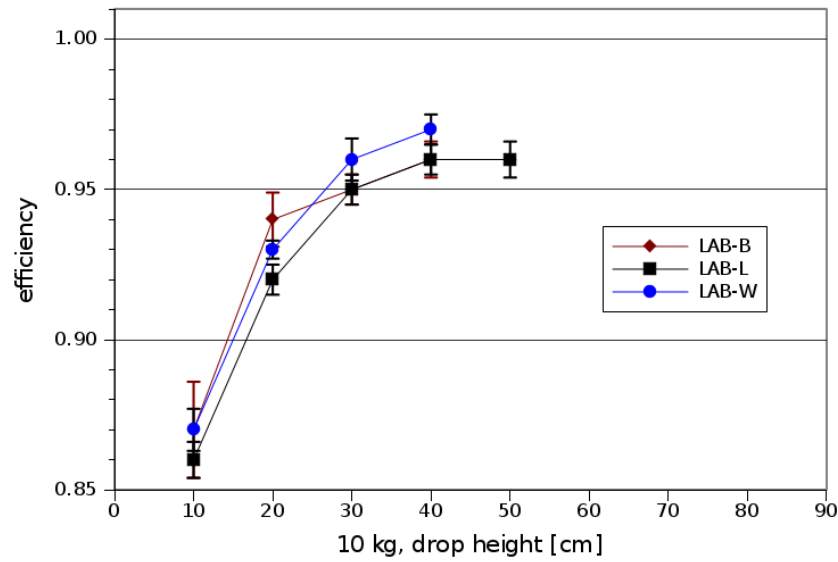

Figure 6. Efficiency (q) of conversion of potential energy to kinetic energy, $10 \mathrm{~kg}$.

The second analysis shown here is the amount of energy returned to the drop weight when no substance is involved. Or, to look at the opposite aspect, how much energy is lost in the foundations and which is expected to be unavailable for initiation of a test substance. Figures 7 to 9 show graphs for the $k$-value with error bars. Higher $k$-values mean a better return of the downward kinetic energy into upward kinetic energy. The error bars are again taken from the standard deviation of the 10 repetitions (respectively 5) of the drops.

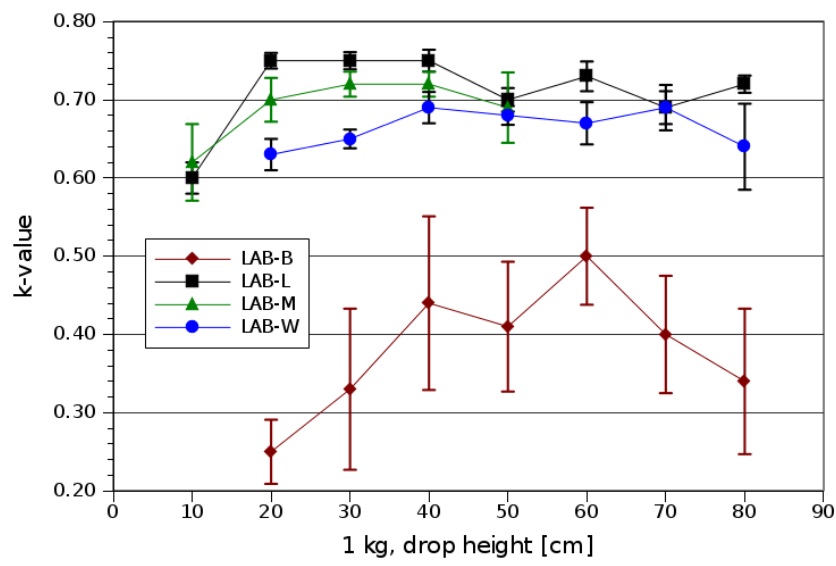

Figure 7. k-value comparison for $1 \mathrm{~kg}$ drop weight. 


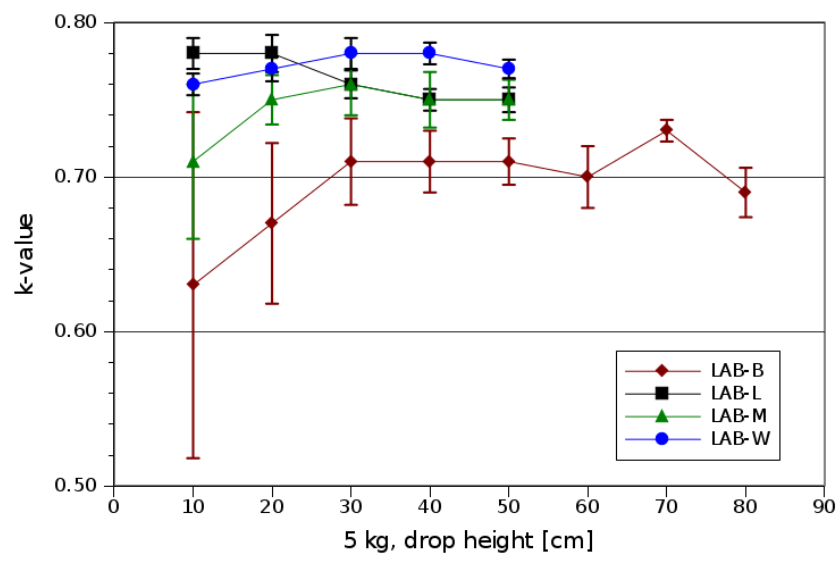

Figure 8. k-value comparison for $5 \mathrm{~kg}$ drop weight.

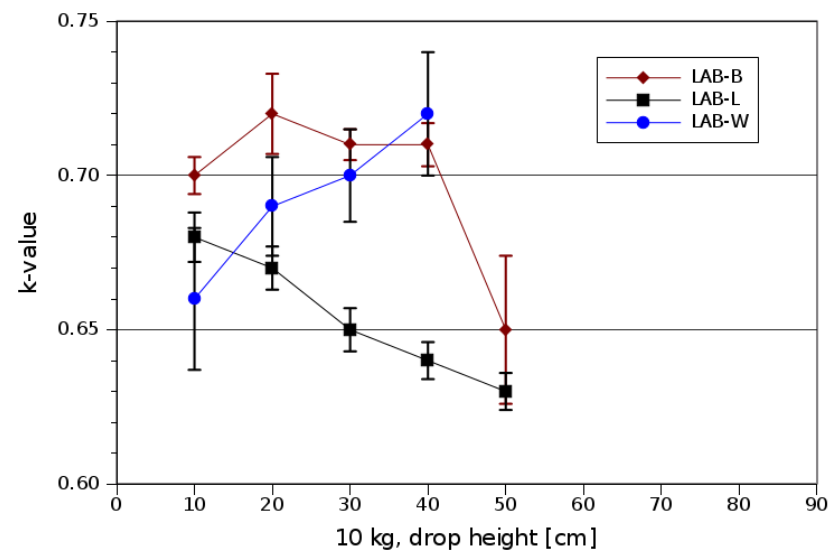

Figure 9. k-value comparison for $10 \mathrm{~kg}$ drop weight.

From the graphs it can be seen, that the conversion of potential energy to kinetic energy takes place mostly in a consistent way. Disregarding the results for the $10 \mathrm{~cm}$ drop height, which seems to be an unfavourable drop height to be used, the efficiency $q$ is generally around and above $90 \%$. The $k$-value, indicating the amount of energy returned after the impact, shows stronger differences between the instruments. 


\section{Conclusions}

The principal motivation for undertaking this work was to compare different Fallhammers with regard to their mechanical properties and to find characteristic technical parameters. In Round-Robin-tests on the impact sensitivity of explosives it has been observed that results for the same substance can be quite divergent. The reasons for this could be manifold, including the uncertainty factor of the operator, who has to decide whether a reaction occurred or not. A valid question in this context would be: how much do mechanical differences between different Fallhammers contribute to deviating results?

A second perspective to this purely mechanical study is to start defining tolerable limits for the mechanical characteristics of a Fallhammer, thus allowing for verification, calibration, or quality control aspects of the measurement of impact sensitivity in future. Below a first attempt is made to establish limiting values for the mechanical performance of a Fallhammer. It may be a matter of adding more results before a performance criterion for the Fallhammer can be set in stone (or fixed as a quality standard). However, the above results have a highly suggestive capability already and should be good for characterisation of a Fallhammer on an informal basis.

It is proposed that, when mechanical data are recorded according to the example given in this paper, the Fallhammer is assessed according to Table 7. This table gives three levels of assessment, two levels of which are sufficient for most purposes. Under normal circumstances it is sufficient to know if the instrument operates in an acceptable range, or if the performance is not acceptable and action is needed. However, for the purpose of Round-Robintests those instruments fulfilling a "very good" criterion could act as reference instruments defining the target values to be achieved in a Round-Robin-test by other participants.

At this moment in time the limiting values in Table 7 were taken from the data as the lowest observed level, rounded to the next lower percentage. The figures are given in square brackets to indicate that these are set provisionally. Where other laboratories test their Fallhammer, this should serve as a guide. Apart from the proposed limits, the measurement of $q$ and of $k$ over a period of time and for a specific instrument can be used to monitor the stability of the instrument and to reveal defects, which may occur after a period of use. 
Table 7. Limiting mechanical properties of the Fallhammer

\begin{tabular}{|c|c|c|c|}
\hline Property & $\begin{array}{l}\text { Symbol } \\
\text { used in this } \\
\text { paper }\end{array}$ & Criterion & Assessment \\
\hline \multirow{3}{*}{$\begin{array}{l}\text { Conversion efficiency } \\
\text { from potential to } \\
\text { kinetic energy }\end{array}$} & \multirow{3}{*}{$q$} & $\begin{array}{c}1 \mathrm{~kg} \text { drop weight, } \\
\text { drop height } \geq 20 \mathrm{~cm} \\
>92 \% \\
\geq 82 \% \\
<82 \%\end{array}$ & $\begin{array}{c}\text { very good } \\
\text { acceptable } \\
\text { not acceptable* }\end{array}$ \\
\hline & & $\begin{array}{c}5 \mathrm{~kg} \text { drop weight, } \\
\text { drop height } \geq 20 \mathrm{~cm} \\
>95 \% \\
\geq 92 \% \\
<92 \%\end{array}$ & $\begin{array}{c}\text { very good } \\
\text { acceptable } \\
\text { not acceptable* }\end{array}$ \\
\hline & & $\begin{array}{c}10 \mathrm{~kg} \text { drop weight, } \\
\text { drop height } \geq 20 \mathrm{~cm} \\
>95 \% \\
\geq 91 \% \\
<91 \%\end{array}$ & $\begin{array}{c}\text { very good } \\
\text { acceptable } \\
\text { not acceptable* }\end{array}$ \\
\hline \multirow{3}{*}{$\begin{array}{l}\text { Ratio of kinetic } \\
\text { energies from } \\
\text { upwards to } \\
\text { downwards } \\
\text { movement }\end{array}$} & \multirow{3}{*}{$k$} & $\begin{array}{c}1 \mathrm{~kg} \text { drop weight, } \\
\text { drop height } \geq 20 \mathrm{~cm} \\
>70 \% \\
\geq 62 \% \\
<62 \%\end{array}$ & $\begin{array}{c}\text { very good } \\
\text { acceptable } \\
\text { not acceptable* }\end{array}$ \\
\hline & & $\begin{array}{c}5 \mathrm{~kg} \text { drop weight, } \\
\text { drop height } \geq 20 \mathrm{~cm} \\
>76 \% \\
\geq 74 \% \\
<74 \%\end{array}$ & $\begin{array}{c}\text { very good } \\
\text { acceptable } \\
\text { not acceptable* }\end{array}$ \\
\hline & & $\begin{array}{c}10 \mathrm{~kg} \text { drop weight, } \\
\text { drop height } \geq 20 \mathrm{~cm} \\
>69 \% \\
\geq 65 \% \\
<65 \%\end{array}$ & $\begin{array}{c}\text { very good } \\
\text { acceptable } \\
\text { not acceptable* }\end{array}$ \\
\hline
\end{tabular}

* requires maintenance

In choosing the values for Table 7 the standard deviation from the repetitions and clustering of values from different laboratories were taken into account. This was, however, more an intuitive process, and the Figures 4 to 9 were taken into account, too. Further progress will be possible once the measurements have been repeated at the same laboratories and something like the repeatability 
standard deviation becomes available. The authors plan to continue this work. Independent work on this subject would be beneficial and could help to consolidate the values in Table 7, and in future define a clear borderline between an "accurately operating" and a "poorly operating" Fallhammer.

\section{Acknowledgements}

This work was made possible through the help of the following people and institutions:

- Dr. Rasmus Schulte-Ladbeck, Federal Criminal Police Office (BKA) in Germany,

- Dr. Dirk Cegiel, Rheinmetall Waffe Munition GmbH, Branch Nico Trittau in Germany,

- Dr. Michel Lefebvre, Royal Military Academy (RMA) in Belgium,

- Dipl.-Ing. Dietmar Hey, Technical Center for Weapons and Ammunition (WTD 91) in Germany.

The support by the teams of the respective groups and their technical skill is especially appreciated.

\section{References}

[1] Manual of Tests and Criteria, $5^{\text {th }}$ revised ed., ST/SG/AC.10/11/Rev.5, 2009, United Nations, Ch. 13.4.2: Test 3 (a) (ii): BAM Fallhammer.

[2] ISO/IEC 17043:2010 (E), Conformity Assessment - General Requirements for Proficiency Testing.

[3] ISO 5725, Accuracy (Trueness and Precision) of Measurement Methods and Results, Parts 1-6, 1994-2005. 